\title{
$\beta$-catenin promotes MTX resistance of leukemia cells by down-regulating FPGS expression via NF-kB
}

\author{
Shu-Guang Liu* ${ }^{*}$, Zhi-Xia Yue, Zhi-Gang Li, Rui-Dong Zhang, Hu-Yong Zheng, Xiao-Xi Zhao and Chao Gao*
}

\begin{abstract}
Background: Aberrant activation of $\beta$-catenin has been shown to play important roles in the chemoresistance of acute lymphoblastic leukemia (ALL), but the involvement and mechanism of $\beta$-catenin in methotrexate (MTX) resistance is poorly understood. In the present study, we demonstrate a critical role of $\beta$-catenin-NF-KB-FPGS pathway in MTX resistance in the human T-lineage ALL cell lines.
\end{abstract}

Methods: Lentivirus sh- $\beta$-catenin was used to silence the expression of $\beta$-catenin. Flow cytometry was performed to detect apoptosis after MTX treatment. Western blot, real-time PCR, Co-immunoprecipitation (Co-IP), Chromatin immunoprecipitation (ChIP), Re-ChIP, and Luciferase assay were utilized to investigate the relationship among $\beta$-catenin, nuclear factor (NF)-KB, and folypoly- $\gamma$-glutamate synthetase (FPGS).

Results: Depletion of $\beta$-catenin significantly increased the cytotoxicity of MTX. At the molecular level, knockdown of $\beta$-catenin caused the increase of the protein level of FPGS and NF-KB p65. Furthermore, $\beta$-catenin complexed with NF-kB p65 and directly bound to the FPGS promoter to regulate its expression. In addition, $\beta$-catenin repression prolonged the protein turnover of FPGS.

Conclusions: Taken together, our results demonstrate that $\beta$-catenin may contribute to MTX resistance in leukemia cells via the $\beta$-catenin-NF-KB-FPGS pathway, posing $\beta$-catenin as a potential target for combination treatments during ALL therapy.

Keywords: Acute lymphoblastic leukemia, Drug resistance, Folylpolyglutamate synthetase, Methotrexate, $\beta$-catenin

\section{Introduction}

$\mathrm{T}$ cell acute lymphoblastic leukemia (T-ALL) is an aggressive hematological malignancy that accounts for about $15 \%$ of pediatric acute lymphoblastic leukemia. Despite of significant improvements in therapy, a number of childhood T-ALL patients experience relapse and face a dismal prognosis. Drug resistance is a key factor contributing to relapse $[1,2]$. Thus, understanding the

\footnotetext{
*Correspondence: shuguangliubch@126.com; gaochaoconnie@live.cn Beijing Key Laboratory of Pediatric Hematology Oncology, National Key Discipline of Pediatrics, Ministry of Education, Key Laboratory of Major Diseases in Children, Ministry of Education, Hematology Oncology Center, Beijing Children's Hospital, Capital Medical University, 56 Nanlishi Road, Beijing 100045, China
}

molecular basis for chemoresistance may pave the way for improving drug sensitivity and prognosis.

Methotrexate (MTX) is a major component in all contemporary treatment protocols for childhood ALL, but emergence of resistance to MTX remains an obstacle towards curative chemotherapy [3, 4]. Folypoly$\gamma$-glutamate synthetase (FPGS) is responsible for the activation of MTX to MTX polyglutamates (MTXPGs). The ability of leukemia cells to accumulated MTXPGs was shown to be a determinant of MTX activity in childhood ALL patients. Consequently, loss of FPGS activity is a well-established mechanism of resistance to MTX in vitro and in vivo [5-7]. FPGS activity is significantly correlated with FPGS mRNA levels. In childhood ALL, a 
strong correlation exists between FPGS expression, intracellular MTXPGs accumulation and treatment outcome. T-ALL patients fare worse than other patients treated with antimetabolite-based chemotherapy regimens, resulting from significantly lower FPGS expression, FPGS activity, and MTXPGs accumulation [8, 9]. There are few previous studies on the FPGS transcription regulation. It is reported that HDAC1 is recruited by NFY-B and Sp1 proteins to the FPGS promoter in a multiprotein complex that includes CBP, to regulate FPGS mRNA expression epigenetically through chromatin remodeling [10]. Some fusion proteins, such as TEL-AML1 and E2A-PBX1, can also suppress FPGS transcription by recruiting co-repressors (mSin $3 \mathrm{~A}, \mathrm{Rb})$ and HDAC1 to the FPGS promoter region [11]. Further study is required to better understanding the mechanisms that control FPGS expression in T-ALL, which could lead to the development of novel targets capable of upregulating FPGS and increasing MTXPGs accumulation.

In order to find novel transcription factors for FPGS regulation, we analyzed the promoter region of FPGS and found two potential NF- $\mathrm{kB}$ p65 binding sites, indicating that NF- $\mathrm{kB}$ might be a transcription factor for FPGS. Previous study suggested that $\beta$-catenin can complex with NF-kB, inhibit NF- $\mathrm{kB}$ activity and repress its target genes in human colon and breast cancer cells [12]. $\beta$-catenin can also complex with HDAC1 to regulate target genes [13]. So $\beta$-catenin is probably involved in the FPGS regulation. It is reported that $\beta$-catenin contributes to MTX resistance in osteosarcoma and colorectal cancer. Ma et al. [14] found that $\beta$-catenin knockdown increased the sensitivity of osteosarcoma cell line Saos2 to MTX-induced cell death. The Wnt/ $\beta$-catenin signaling was activated in a MTX-resistant colorectal cell line HT-29 (HT-29-R) [15]. But the role of $\beta$-catenin in MTX resistance in ALL has not been clarified.

In this study, we found that $\beta$-catenin promoted MTX resistance in T-ALL cells. Mechanistically, we showed that $\beta$-catenin can interact with NF-kB p65 and repressed the protein expression of $\mathrm{p} 65$. Importantly, $\beta$-catenin was found to inhibit the expression of NF- $\mathrm{kB}$ p 65 target gene FPGS. Thus, our data reveal a novel $\beta$-catenin-NF- $k B$ FPGS pathway involved in MTX resistance and suggest that targeting $\beta$-catenin may be a therapeutic strategy for combined therapy.

\section{Materials and methods}

\section{Cell culture and treatments}

The human T-lineage ALL cell line Jurkat, CCRF-CEM, MOLT4, and human embryonic kidney (HEK)-293 were purchased from the cell bank at Peking Union Medical University. Jurkat, MOLT4, and CCRF-CEM were cultured in RPMI 1640 (Invitrogen) supplemented with
$10 \%$ fetal bovine serum (FBS, Invitrogen), penicillin (100 $\mathrm{U} / \mathrm{mL}$ ), and streptomycin (100 mg/mL). HEK-293 was cultured in Dulbecco's Modification of Eagle's Medium with $10 \% \mathrm{FBS}$, penicillin $(100 \mathrm{U} / \mathrm{mL})$, and streptomycin (100 mg/mL).

hCTNNB1 knockdown was carried out using lentivirus containing shRNA-1 oligonucleotide: $5^{\prime}$-TTG GAATGAGACTGCTGAT-3' and shRNA-2 oligonucleotide: 5'-CATGGAAGAAATAGTTGAA-3' . A scrambled shRNA lentivirus with no effect on hCTNNB1 was constructed as a negative control using the following sequence: TTCTCCGAACGTGTCACGT (GeneChem Co. Ltd. China).

Jurkat was treated with the NF-kB inhibitor, pyrrolidine dithiocarbamate (PDTC; $100 \mu \mathrm{M}$; Sigma-Aldrich), NF- $\kappa$ B stimulant lipopolysaccharides (LPS; $1 \mu \mathrm{g} / \mathrm{mL}$; SigmaAldrich), and Canonical WNT signaling inhibitor PRI$724(20 \mu \mathrm{M}$; Selleck) respectively for $20 \mathrm{~h}$ to investigate whether FPGS was regulated by the NF- $\mathrm{kB}$ and WNT pathway. To examine the effect of $\beta$-catenin on MTX resistance, cells were treated for $24 \mathrm{~h}$ with $10 \mu \mathrm{M}$ MTX at $48 \mathrm{~h}$ posttransfection of RNAi lentivirus. To examine the protein turnover of FPGS, cells were treated with a protein biosynthesis inhibitor cycloheximide (CHX, MCE) at a final concentration of $50 \mu \mathrm{g} / \mathrm{mL}$ for $0,2,4$, and $8 \mathrm{~h}$, respectively.

\section{Sample preparation}

Bone marrow (BM) samples of patients were collected at diagnosis. Mononuclear cell separation was carried out as previously described [16] and immediately stored at $-70{ }^{\circ} \mathrm{C}$ until use. This study was approved by the $\mathrm{BCH}$ Institutional Ethics Committee and informed consent according to the Declaration of Helsinki was signed by the guardians of the patients.

\section{RNA isolation and real-time PCR}

Total RNA was isolated using Trizol reagent (Invitrogen) according to the manufacturer's instructions. Isolated RNA was used as a template for the reverse transcription reaction (Invitrogen). Quantitative real-time PCR analysis was carried out using PowerUP SYBR Green Master Mix (Applied Biosystems) on ViiA 7 System (Applied Biosystems). Glyceraldehyde 3 phosphate dehydrogenase (GAPDH) was used as a loading control. The primers are listed in Additional file 1: Table S1.

\section{Western blot analysis}

Proteins were separated by SDS-PAGE, transferred to polyvinylidene difluoride membranes (Millipore), blocked and probed with antibodies against $\beta$-catenin (1:1000; Cell Signaling Technology), p65 (1:1000; Cell Signaling Technology), GAPDH (1:4000; Santa Cruz), 
and FPGS (1:1000; Abcam). After washing, blots were incubated with horseradish peroxidase-conjugated secondary antibodies and visualized by super enhanced chemiluminescene (ECL) detection reagent (Appygen).

\section{Plasmid construction}

Regions of FPGS gene promoter were generated by PCR using genomic DNA extracted from CCRF-CEM cells, and cloned into pGL3-basic vector (Promega). Primers used for this study are listed in Additional file 1: Table S1. All constructs were confirmed by Sanger sequencing.

\section{Assessment of apoptosis}

Cells were treated with Annexin V Apoptosis Detection Kit APC (eBioscience) and analyzed using flow cytometry after treatment with MTX.

\section{Luciferase assay}

The luciferase reporter assays were performed in triplicate by the Dual-Luciferase Reporter Assay Kit (TransDetect). HEK-293 cells were transiently transfected with luciferase reporter plasmids (pGL3-FPGS WT, pGL3FPGS MUT-1, pGL3-FPGS MUT-2, and pGL3-Basic). Transfection efficiency was measured by co-transfection with a Renilla luciferase expression plasmid pRL-SV40 (Promega). The data were presented as the ratio of firefly luciferase activity to Renilla luciferase activity and results were presented as the mean \pm SD.

\section{Chromatin immunoprecipitation (ChIP) and Re-ChIP}

ChIP and Re-ChIP assays were performed using the ChIP-IT $^{\circledR}$ Express Chromatin Immunoprecipitation Kits and Re-ChIP-IT ${ }^{\circledR}$ kits (Active Motif), according to the manufacturer's instructions. Chromatin samples were immunoprecipitated with either anti-RelA antibody (Cell Signaling Technology) or normal mouse IgG (Cell Signaling Technology) as a negative control. Precipitated DNA was amplified by PCR using primers provided in the Additional file 1: Table S1. Non-immunoprecipitated chromatin fragments were used as an input control.

\section{Statistical analysis}

The differences in results between groups were compared using Student's $t$ test. Data were expressed as mean \pm SD. All statistical analyses were performed with the SPSS 16.0 Statistical program for Windows. $P$ values less than 0.05 were considered significant.

\section{Results}

\section{Reduction of $\beta$-catenin expression decreases MTX} resistance in T-ALL cells

To investigate the effect of $\beta$-catenin on MTX resistance, Jurkat and MOLT4 cells expressing high levels of $\beta$-catenin (Additional file 2: Figure S1) were transfected with $\beta$-catenin RNAi lentivirus for $48 \mathrm{~h}$ and then treated with $10 \mu \mathrm{M}$ MTX for an additional 24 h. Flow cytometric results showed that the percentage of apoptosis cells were much higher in the $\beta$-catenin RNAi groups, compared with the sh-Control group (Fig. 1). These data revealed that $\beta$-catenin expression promotes MTX resistance.

\section{$\beta$-catenin inhibits the protein level of FPGS in T-ALL cells}

Given that FPGS is responsible for MTX activation and FPGS downregulation leads to resistance to MTX [5-7], we tested whether inhibition of $\beta$-catenin would affect the expression of FPGS. Western blot results showed that the protein level of FPGS was significantly increased after $\beta$-catenin depletion (Fig. 2a, b), demonstrating that $\beta$-catenin may suppress FPGS protein expression in ALL cells. After treatment of MTX at the concentration of $10^{-8} \mathrm{M}$ for 2 weeks, the protein expression level of FPGS increased and that of $\beta$-catenin decreased, which confirmed the regulation between them (Fig. 2c).

\section{$\beta$-catenin regulates FPGS expression through interacting with NF-KB p65}

Previous study suggested that $\beta$-catenin can complex with NF- $\mathrm{kB}$, inhibit NF- $\mathrm{kB}$ activity and repress its target genes in human colon and breast cancer cells [12]. Therefore, we hypothesized that $\beta$-catenin might regulate FPGS expression via NF- $\mathrm{kB}$ in ALL cells. As shown in Fig. 3a, after treatment of Jurkat cells with PDTC, a selective NF- $k B$ inhibitor, the FPGS mRNA levels were significantly decreased. Moreover treatment with NF- $\kappa B$ stimulant LPS can dramatically increase the FPGS mRNA level (Fig. 3b). These data indicated that NF-kB p65 might regulate FPGS expression at the transcription level.

We next search the promoter region of FPGS and found two potential NF-kB p65 binding sites (Fig. 3c). To further confirm the transcriptional regulation of FPGS by $\mathrm{p} 65$, we subsequently generated a luciferase reporter vector, pGL3-FPGS WT, with FPGS promoter fragment $(-684 \sim 34)$. Deletion of the two p65 binding sites (MUT-1 for site 1 and MUT-2 for site 2), especially site 1 (-653/644), significantly attenuated the FPGS promoter activity in HEK-293 (Fig. 3d). Moreover, ChIP assays showed that p65 directly bound to the $-653 / 644$ region of the FPGS promoter, and the binding can be inhibited by NF-kB inhibitor PDTC and $\beta$-catenin inhibitor PRI724 (Fig. 3e). These results clearly confirmed that FPGS is a direct transcriptional target of p65 in leukemia cells.

Consistent with previous reports, we found that $\beta$-catenin can also physically complex with NF- $\mathrm{kB}$ p65 (Fig. 4) in Jurkat cells. To futher explore the relationship between $\beta$-catenin and p65, we subsequently test the mRNA and protein levels of p65 after $\beta$-catenin 


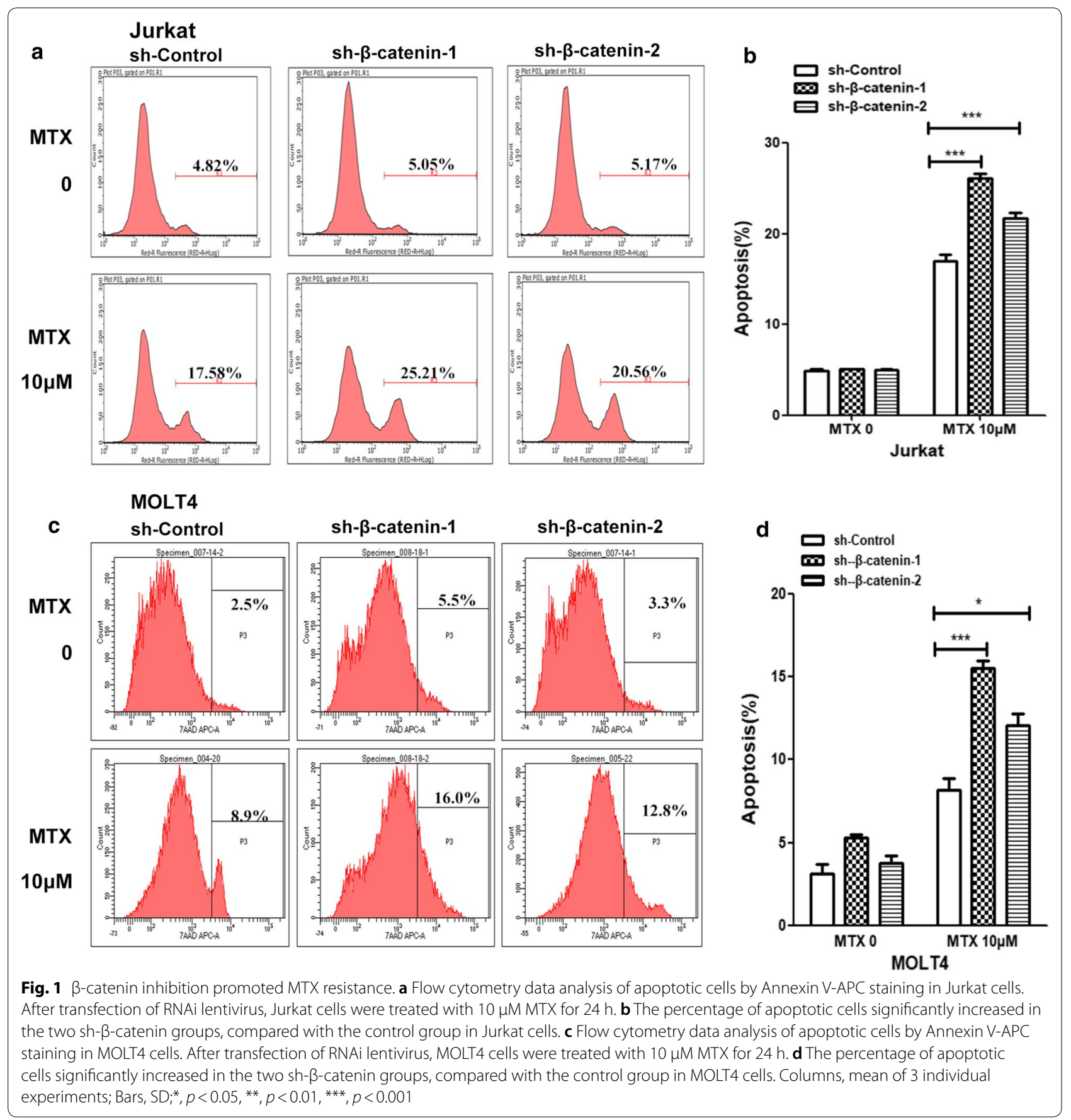

knockdown. The mRNA level of p65 was not changed after $\beta$-catenin repression (data not shown). The protein level of p65 was increased (Fig. 2a, b). In addition, the protein levels of $\beta$-catenin and p65 were inversely correlated (Additional file 2: Figure S1) in ALL cell lines. To validate the interaction between p65 and $\beta$-catenin in the regulation of FPGS, we performed Re-ChIP assay (Fig. 3f). Results showed that p65 and $\beta$-catenin can bind to form a complex on the FPGS promoter in Jurkat cells.

Based on abovementioned data, $\beta$-catenin can inter-

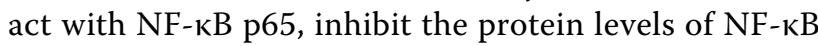
p65 and its novel target gene FPGS in leukemia cells. 


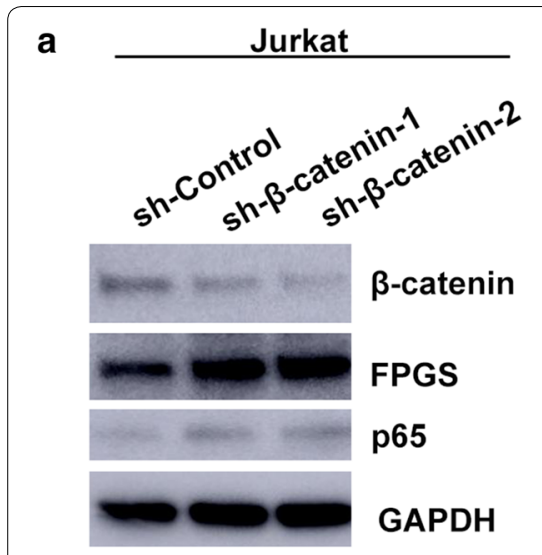

b

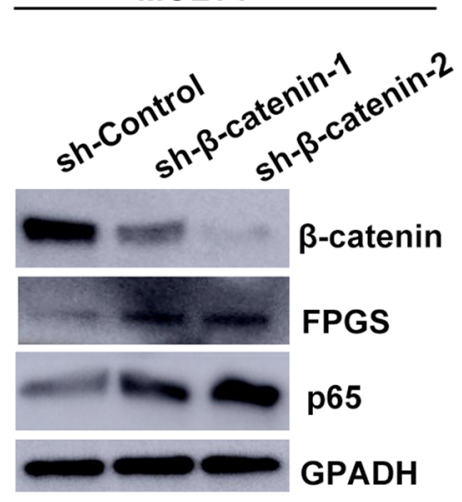

c<smiles>[3H][Mg]</smiles>

g

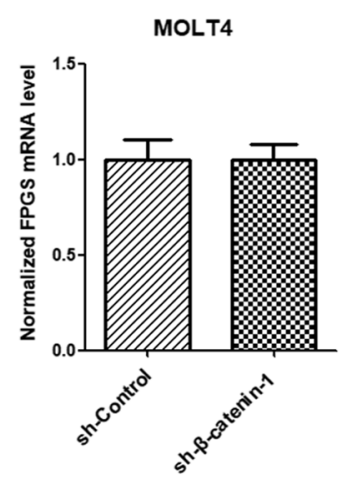

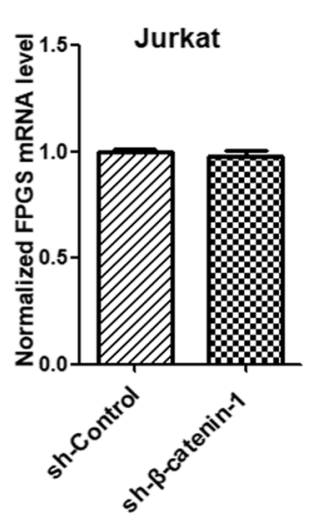

h

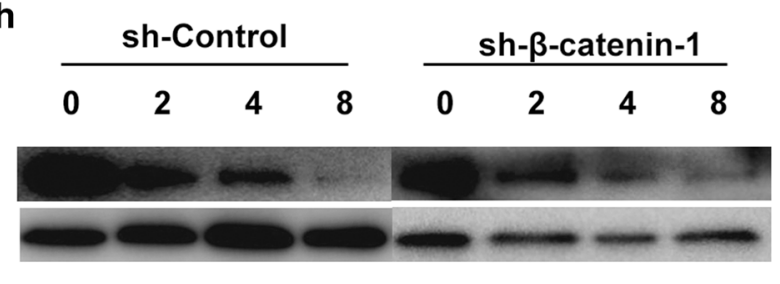

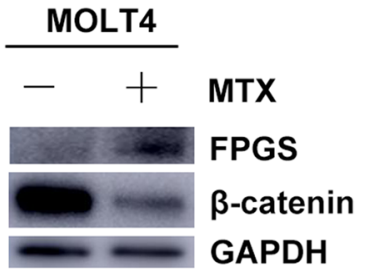

d

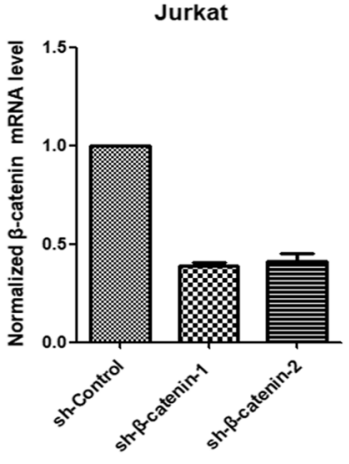

MOLT4

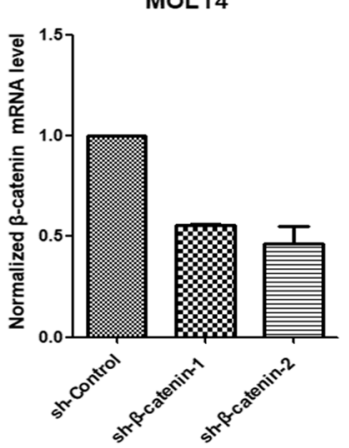

CHX (h)

FPGS

GAPDH

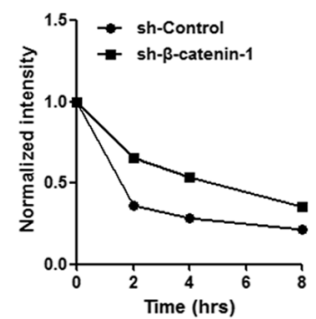

Fig. $2 \beta$-catenin regulated the protein expression of FPGS and NF-KB p65. a Western blot analysis of FPGS and p65 expression after $\beta$-catenin knockdown in Jurkat cells. $\mathbf{b}$ Western blot analysis of FPGS and p65 expression after $\beta$-catenin knockdown in MOLT4 cells. c Western blot analysis of FPGS and $\beta$-catenin expression after treatment with $10^{-8}$ M MTX for 2 weeks in MOLT4 cells. $\mathbf{d}$ The mRNA level of $\beta$-catenin in sh-Control or sh- $\beta$-catenin by qPCR in Jurkat cells. e The mRNA level of $\beta$-catenin in sh-Control or sh- $\beta$-catenin by qPCR in MOLT4 cells. $\mathbf{f}$ The mRNA level of FPGS in sh-Control or sh- $\beta$-catenin by qPCR in Jurkat cells. $\mathbf{g}$ The mRNA level of FPGS in sh-Control or sh- $\beta$-catenin by qPCR in MOLT4 cells. $\mathbf{h}$ Jurkat cells transfected with control shRNA or $\beta$-catenin-targeting shRNA were treated with CHX. The immunoblotting of FPGS and $\beta$-catenin (left) and the relative levels of FPGS (right) were quantifified

\section{$\beta$-catenin might also regulate FPGS protein stability}

Since $\beta$-catenin depletion altered the protein level of FPGS without obvious change in the mRNA levels of FPGS (Fig. 2f, g), we further addressed whether the protein turnover of FPGS has been changed after $\beta$-catenin silencing. Results showed that knockdown of $\beta$-catenin significantly increased the stability of FPGS protein in cells treated with cycloheximide (CHX) (Fig. 2h). These results suggested that $\beta$-catenin might also be involved in the post-translational regulation of FPGS in T-ALL cells.

\section{Discussion}

$\beta$-catenin is reported to be involved in the chemoreistance in many types of cancers $[14,17,18]$, but there are few studies about its effects on drug resistance in ALL [19]. In this study, we have shown a novel role of $\beta$-catenin 


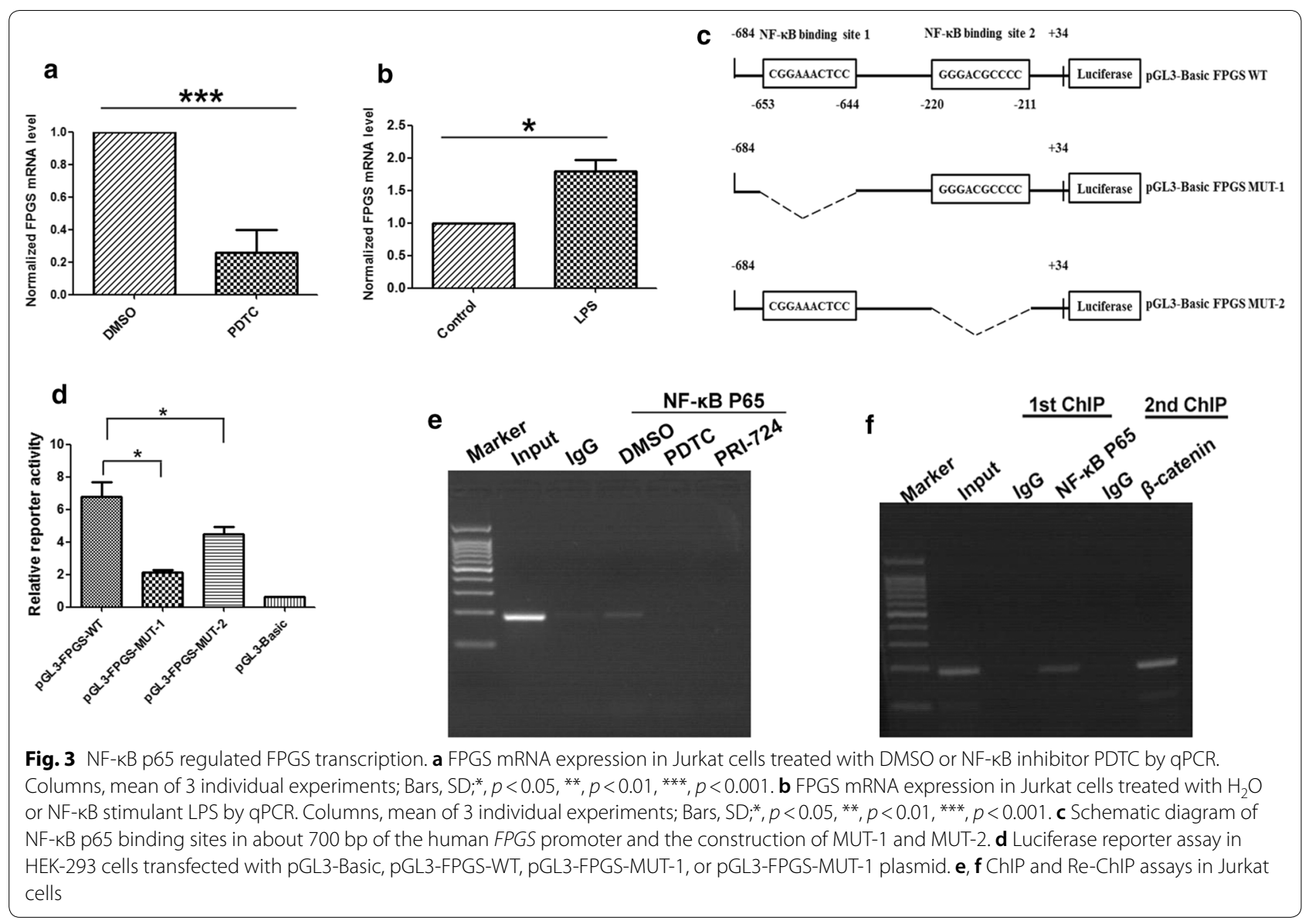

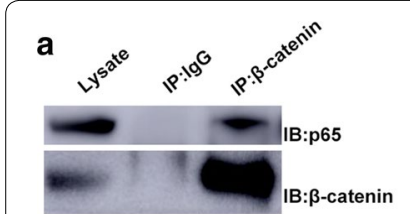

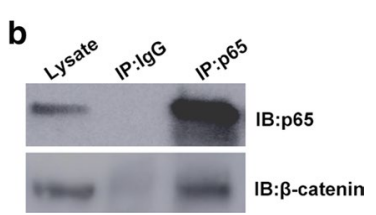

Fig. $4 \beta$-catenin interacted with NF-kB p65 in Jurkat cells. a Immunoprecipitation (IP) was performed with antibodies against $\beta$-catenin (normal lgG as a negative control). The complexes were then subjected to immunoblot as indicated. $\mathbf{b}$ IP was performed with antibodies against NF-KB p65 (normal lgG as a negative control). The complexes were then subjected to immunoblot as indicated

that it promotes MTX resistance in T-ALL cells. In molecular level, we found that $\beta$-catenin transcriptionally regulates FPGS expression by interacting with NF- $\mathrm{kB}$. It can also regulate FPGS protein stability. Therefore, this study identified a novel $\beta$-catenin-NF-kB-FPGS pathway in MTX resistance in leukemia cells.

Previous studies showed that loss of FPGS activity is a mechanism of MTX resistance [5-7]. Transactivation and upregulation of FPGS have been reported to promote the cytotoxicity of MTX. Leclerc et al. [10] found that histone deacetylase 1 (HDAC1) is recruited by NFY-B and Sp1 proteins to the FPGS promoter and epigenetically regulate FPGS mRNA expression. Treatment with HDACi resulted in increased FPGS mRNA expression and higher intracellular accumulation of MTXPGs. We postulated that $\beta$-catenin may contribute to MTX resistance by regulating FPGS. Our data showed that after $\beta$-catenin inhibition the percentage of apoptotic cells significantly increased and the protein level of FPGS was increased, indicating that $\beta$-catenin might promote MTX resistance through inhibiting FPGS.

NF- $\mathrm{KB}$ is a transcription factor that controls multiple cellular processes in cancer including. It has been found to constitutively active in many solid tumors and hematological malignancies including ALL [20-22]. $\beta$-catenin has been shown to physically interact with $\mathrm{NF}-\mathrm{kB}$, inhibits its activity and represses the expression of NF- $\mathrm{kB}$ target gene, such as Fas, Traf1, and hiNOS $[12,23]$. To test whether NF- $\mathrm{kB}$ is involved in the regulation between $\beta$-catenin and FPGS in leukemia cells, we performed coimmunoprecipitation assay and our result is in agreement with other findings that there is a interaction between $\beta$-catenin and p65. Moreover, 
our luciferase, ChIP, and Re-ChIP results indicated that FPGS is a novel target gene of NF- $\mathrm{kB}$ p65. These data demonstrated that NF- $\mathrm{kB}$ might be a mediator for the regulation of FPGS by $\beta$-catenin.

To further examine the relationship between $\beta$-catenin and NF- $k B$ p65, we checked the mRNA and protein levels of p65 after $\beta$-catenin inhibition. There is no change on the mRNA level of p65, showing that $\beta$-catenin did not regulate the transcription of $\mathrm{p} 65$. Interestingly, we found that the protein level of p65 slightly increased after depletion of $\beta$-catenin and the protein expressions of the two molecules were inversely correlated in ALL cell lines (Additional file 2: Figure S1), which implicates that $\beta$-catenin might regulate NF- $\mathrm{kB}$ in the protein level. Previous studies have shown the cross regulation between $\beta$-catenin and NF- $\mathrm{KB}[20$, 24-26]. $\beta$-catenin was found to form a complex with p65 and p50, leading to a decrease in NF- $\mathrm{kB}$ DNA binding and transactivation activity, and target gene expression. Studies revealed a negative effect of $\beta$-catenin on NF- $\mathrm{KB}$ activity and expression of downstream target genes in liver, breast, and colon cancer cells [12, 23, 27]. Such correlation was not seen in head and neck cancer [28]. Our results (Additional file 2: Figure S1 and Additional file 3: Figure S2) and previous study showed that $\beta$-catenin expressed higher in T-ALL samples and cell lines compared to B-ALL [24]. Moreover, it is reported that constitutive NF- $\mathrm{KB}$ activation is common in childhood ALL without any difference between T- and B-ALLs [22], implicating that $\beta$-catenin might not inhibit NF- $\mathrm{KB}$ activity in ALL, which is inconsistent with previous reports in colon, breast, and liver cancer $[12,23,27]$. It is possible that $\beta$-catenin regulates $\mathrm{NF}-\kappa \mathrm{B}$ in a different way in leukemia, and the regulation mechanisms need further investigation. There is a problem that the mRNA level of FPGS is not significantly changed after $\beta$-catenin knockdown, which seems contradictory. Although $\beta$-catenin interacts with p65 and regulates the transcription of FPGS, but the transcriptional regulation of FPGS is complex which involves many pathways [10,11, 29-31], which might be a reason for this result. The CHX result showed that $\beta$-catenin might be also involved in the post-translational regulation of FPGS

Emerging evidence suggest that NF- $\mathrm{kB}$ can act as both tumor-promoting transcription factor and tumor suppressor [31-38]. In our study, p65 positively regulate FPGS transcription, and after inhibition of NF- $\mathrm{kB}$ activity by PDTC in Jurkat cells, the mRNA level of anti-apoptotic gene Bcl2 increased (Additional file 4: Figure S3), implicating a pro-apoptotic role of NF-kB in the MTX induced apoptosis in leukemia cells.

\section{Conclusions}

In summary, our study reveals a novel signal pathway, $\beta$-catenin-NF- $\mathrm{kB}$ p65-FPGS, promoting MTX resistance in leukemia cells. The drug targeting $\beta$-catenin might be used in combination with MTX to overcome MTX resistance in T- ALL patients.

\section{Supplementary information}

Supplementary information accompanies this paper at https://doi. org/10.1186/s12935-020-01364-y.

Additional file 1: Table S1. Primer sequences.

Additional file 2: Figure S1. $\beta$-catenin and NF-KB p65 expression in ALL cell lines. Western blot analysis of $\beta$-catenin and NF-KB protein expression in $5 \mathrm{ALL}$ cell lines.

Additional file 3: Figure S2. $\beta$-catenin protein levels in childhood primary $A L L$ samples. Western blot analysis of $\beta$-catenin protein expression in childhood primary leukemia cell.

Additional file 4: Figure S3. NF-KB inhibited the mRNA expression of $\mathrm{BCl}$ 2. Bcl2 mRNA expression in cells treated with DMSO or NF-KB inhibitor PDTC by qPCR

\section{Abbreviations}

ALL: Acute lymphoblastic leukemia; MTX: Methotrexate; FPGS: Folypoly- $\gamma$ glutamate synthetase; MTXPGs: MTX polyglutamates; AML: Acute myeloid leukemia; FBS: Fetal bovine serum; PDTC: Pyrrolidine dithiocarbamate; BM: Bone marrow; ChIP: Chromatin immunoprecipitation; HDAC1: Histone deacetylase 1.

\section{Acknowledgements}

We gratefully thank all staff of the Hematology \& Oncology Center of Beijing Children's Hospital, Capital Medical University, for their help in sampling.

\section{Authors' contributions}

LSG performed the experiments, analyzed the data, wrote the paper and take primary responsibility for the article. GC performed some experiment and analyzed the data. YZX and ZXX performed some experiments. LZG, ZRD, and ZHY supplied the clinical data. All authors read and approved the final manuscript.

\section{Funding}

This work was partially supported by National Natural Science Foundation of China (No. 81300434, 81870114), Beijing Nova Project (No. Z151100000315093), Beijing Municipal Natural Science Foundation (No.7192066), Major National Science and Technology Projects (No. 2017ZX09304029), Beijing Municipal Administration of Hospitals Clinical Medicine Development of Special Grant (No. ZY201404), Beijing Municipal Administration of Hospitals Deng Feng Program (No.DFL20151101), and the Capital Health and Development of Special Grant (No.2016-1-2091).

\section{Availability of data and materials}

The datasets used and/or analyzed during this study are available from the corresponding authors on reasonable request.

\section{Ethics approval and consent to participate}

This research was approved by the Beijing Children's Hospital Institutional Ethics Committee. Informed consents were obtained from the parents or guardians of each patient according to the Declaration of Helsinki.

\section{Consent for publication}

All authors had full access to all of the data in the study and had final responsibility for the decision to submit for publication.

\section{Competing interests}

The authors declare that they have no competing interests. 
Received: 13 September 2019 Accepted: 18 June 2020

Published online: 24 June 2020

\section{References}

1. Pui CH, Evans WE. Treatment of acute lymphoblastic leukemia. N Engl J Med. 2006;354(2):166-78.

2. Aifantis I, Raetz E, Buonamici S. Molecular pathogenesis of T-cell leukaemia and lymphoma. Nat Rev Immunol. 2008;8(5):380-90.

3. Pui $\mathrm{CH}$, Campana D, Pei D, et al. Treating childhood acute lymphoblastic leukemia without cranial irradiation. N Engl J Med. 2009;360(26):2730-41.

4. Wojtuszkiewicz A, Peters GJ, van Woerden NL, et al. Methotrexate resistance in relation to treatment outcome in childhood acute lymphoblastic leukemia. J Hematol Oncol. 2015;8:61.

5. Liani E, Rothem L, Bunni MA, et al. Loss of folylpoly-gamma-glutamate synthetase activity is a dominant mechanism of resistance to polyglutamylation-dependent novel antifolates in multiple human leukemia sublines. Int J Cancer. 2003;103:587-99.

6. Liani E, Rothem L, Bunni MA, et al. Decreased folylpolyglutamate synthetase activity as a mechanism of methotrexate resistance in CCRF-CEM human leukemia sublines. J Biol Chem. 1991:266:6181-7.

7. Masson E, Relling MV, Synold TW, et al. Accumulation of methotrexate polyglutamates in lymphoblasts is a determinant of antileukemic effects in vivo. A rationale for high-dose methotrexate. J Clin Invest. 1996;97:73-80.

8. Galpin AJ, Schuetz JD, Masson E, et al. Differences in folylpolyglutamate synthetase and dihydrofolate reductase expression in human B-lineage versus T-lineage leukemic lymphoblasts: mechanisms for lineage differences in methotrexate polyglutamylation and cytotoxicity. Mol Pharmacol. 1997:52:1551-63.

9. Rots MG, Willey JC, Jansen $\mathrm{G}$, et al. mRNA expression levels of methotrexate resistance-related proteins in childhood leukemia as determined by a standardized competitive template-based RT-PCR method. Leukemia. 2000:14:2166-75

10. Leclerc GJ, Mou C, Leclerc GM, et al. Histone deacetylase inhibitors induce FPGS mRNA expression and intracellular accumulation of long-chain methotrexate polyglutamates in childhood acute lymphoblastic leukemia: implications for combination therapy. Leukemia. 2010;24(3):552-62.

11. Leclerc GJ, Sanderson C, Hunger S, et al. Folylpolyglutamate synthetase gene transcription is regulated by a multiprotein complex that binds the TEL-AML1 fusion in acute lymphoblastic leukemia. Leuk Res. 2010;34(12):1601-9.

12. Deng J, Miller SA, Wang HY, et al. $\beta$-catenin interacts with and inhibits NF-K B in human colon and breast cancer. Cancer Cell. 2002;2:323-34.

13. Lei $A$, Chen $L$, Zhang $M$, et al. EZH2 regulates protein stability via recruiting USP7 to mediate neuronal gene expression in cancer cells. Front Genet. 2019:10:422

14. Ma Y, Ren $Y$, Han EQ, et al. Inhibition of the Wnt- $\beta$-catenin and Notch signaling pathways sensitizes osteosarcoma cells to chemotherapy. Biochem Biophys Res Commun. 2013;431(2):274-9.

15. Wu KF, Liang WC, Feng $L$, et al. $\mathrm{H} 19$ mediates methotrexate resistance in colorectal cancer through activating Wnt/B-catenin pathway. Exp Cell Res. 2017;350(2):312-7.

16. Gao C, Zhao XX, Li WJ, et al. Clinical features, early treatment responses, and outcomes of pediatric acute lymphoblastic leukemia in China with or without specific fusion transcripts: a single institutional study of 1004 patients. Am J Hematol. 2012;87(11):1022-7.

17. Wickström M, Dyberg C, Milosevic J, et al. Wnt/B-catenin pathway regulates MGMT gene expression in cancer and inhibition of Wnt signalling prevents chemoresistance. Nat Commun. 2015;6:8904.

18. Liang $X, X u X$, Wang $F$, et al. E-cadherin knockdown increases $\beta$-catenin reducing colorectal cancer chemosensitivity only in three-dimensional cultures. Int J Oncol. 2015;47(4):1517-27.
19. Dandekar S, Romanos-Sirakis E Pais F et al Wnt inhibition leads to improved chemosensitivity in paediatric acute lymphoblastic leukaemia. Br J Haematol. 2014;167(1):87-99.

20. Chaturvedi MM, Sung B, Yadav VR, et al. NF-kB addiction and its role in cancer: 'one size does not fit all'. Oncogene. 2011;30(14):1615-30.

21. Perkins ND. The diverse and complex roles of NF-kB subunits in cancer. Nat Rev Cancer. 2012;12(2):121-32.

22. Kordes U, Krappmann D, Heissmeyer $V$, et al. Transcription factor NFkappaB is constitutively activated in acute lymphoblastic leukemia cells. Leukemia. 2000;14(3):399-402.

23. Du Q, Zhang X, Cardinal J, et al. Wnt/beta-catenin signaling regulates cytokine-induced human inducible nitric oxide synthaseexpression by inhibiting nuclear factor-kappaB activation in cancer cells. Cancer Res. 2009;69(9):3764-71.

24. Du Q, Geller DA. Cross-regulation between Wnt and NF-KB signaling pathways. For Immunopathol Dis Therap. 2010;1(3):155-81.

25. Ma B, Hottiger MO. Crosstalk between Wnt/ $\beta$-Catenin and NF-kB Signaling Pathway during Inflammation. Front Immunol. 2016;7:378.

26. Liu J, Liao Y, Ma K, et al. PI3K is required for the physical interaction and functional inhibition of NF-KB by $\beta$-catenin in colorectal cancer cells. Biochem Biophys Res Commun. 2013;434(4):760-6.

27. Moreau M, Mourah S, Dosquet C. $\beta$-Catenin and NF-kB cooperate to regulate the uPA/UPAR system in cancer cells. Int J Cancer. 2011;128(6):1280-92.

28. Rodriguez-Pinilla M, Rodriguez-Peralto JL, Hitt R, et al. Beta-Catenin, NfKappaB and FAS protein expression are independent events in head and neck cancer: study of their association with clinical parameters. Cancer Lett. 2005;230(1):141-8.

29. Stark M, Wichman C, Avivi I, et al. Aberrant splicing of folylpolyglutamate synthetase as a novel mechanism of antifolate resistance in leukemia. Blood. 2009:113(18):4362-9.

30. Wojtuszkiewicz A, Raz S, Stark M, et al. Folylpolyglutamate synthetase splicing alterations in acute lymphoblastic leukemia are provoked by methotrexate and other chemotherapeutics and mediate chemoresistance. Int J Cancer. 2016;138(7):1645-56.

31. Yu W, Min D, Lin F, et al. SKA1 induces de novo MTX-resistance in osteosarcoma through inhibiting FPGS transcription. FEBS J. 2019:286(12):2399-414.

32. Karin M. Nuclear factor-kappaB in cancer development and progression. Nature. 2006;441(7092):431-6.

33. Klein U, Ghosh S. The two faces of NF-KB signaling in cancer development and therapy. Cancer Cell. 2011:20(5):556-8.

34. Karl S, Pritschow Y, Volcic M, et al. Identification of a novel pro-apopotic function of NF-kappaB in the DNA damage response. J Cell Mol Med. 2009;13(10):4239-56.

35. Chien Y, Scuoppo C, Wang $X$, et al. Control of the senescenceassociated secretory phenotype by NF-kB promotes senescence and enhances chemosensitivity. Genes Dev. 2011;25(20):2125-36.

36. Jing $\mathrm{H}$, Kase J, Dörr JR, et al. Opposing roles of NF-KB in anti-cancer treatment outcome unveiled by cross-speciesinvestigations. Genes Dev. 2011:25(20):2137-46.

37. Jennewein C, Karl S, Baumann B, et al. Identification of a novel proapoptotic role of NF-KB in the regulation of TRAIL- and CD95-mediated apoptosis of glioblastoma cells. Oncogene. 2012;31(11):1468-74.

38. Abe N, Hou DX, Munemasa S, et al. Nuclear factor-kappaB sensitizes to benzyl isothiocyanate-induced antiproliferation in p53-deficient colorectal cancer cells. Cell Death Dis. 2014;5:e1534

\section{Publisher's Note}

Springer Nature remains neutral with regard to jurisdictional claims in published maps and institutional affiliations. 